\title{
Addition of 5-fluorouracil to docetaxel/cisplatin does not improve survival in locoregionally advanced nasopharyngeal carcinoma
}

\section{ABSTRACT}

Addition of induction chemotherapy (IC) to concurrent chemoradiotherapy (CCRT) is a potentially effective approach for treating locoregionally advanced nasopharyngeal carcinoma (NPC). In this study, we compared the efficacy and toxicity of IC regimens consisting of docetaxel plus cisplatin with (TPF) or without (TP) 5-fluorouracil followed by CCRT in these patients. Clinical data from 245 propensity score-matched pairs of newly diagnosed non-metastatic NPC patients who received either TPF or TP IC before CCRT were retrospectively reviewed. After a median follow-up of 60 months, 5-year locoregional relapse-free, distant metastasis-free, progression-free, and overall survival rates were $95.6 \%, 94.7 \%, 90.4 \%$, and $92.9 \%$ in TPF arm patients and $96.7 \%, 94.2 \%, 91.7 \%$, and $91.0 \%$ in TP arm patients, respectively. There were thus no differences in survival between the two arms. Multivariate analysis revealed that IC regimen was not an independent prognostic factor for any of the survival outcomes. However, patients who received TP experienced lower incidences of grade $3 / 4$ toxicities than those who received TPF. These results indicate that omission of 5-fluorouracil from TPF-based IC did not affect survival outcomes, but was associated with reduced toxicity, in patients with locoregionally advanced NPC.

\section{INTRODUCTION}

The incidence of nasopharyngeal carcinoma (NPC), which ranges between 15 and 50 cases annually per 100,000 people in Southern China, Singapore, and Malaysia, varies with age, ethnicity, and geographical origin [1]. Radiotherapy (RT) is the standard treatment for NPC due to its anatomical location and high 
radiosensitivity. Approximately $60-70 \%$ of all NPC patients have locoregionally advanced NPC at diagnosis [2]. Intensity modulated radiation therapy (IMRT) has improved locoregional control, but doesn't substantially improve survival outcomes or reduce distant failure rates $[3,4]$. According to a meta-analysis of randomized studies, combining RT with chemotherapy reduces the risk of mortality by $18 \%$ and increases 5 -year survival by 4-6\% [5]. Concurrent chemoradiotherapy (CCRT) with or without adjuvant chemotherapy improves overall survival and has become the standard treatment for locoregionally advanced NPC despite the associated acute toxicities [6-8]. A previous meta-analysis showed that the addition of induction chemotherapy (IC) to CCRT reduced distant failure in locoregionally advanced NPC patients $[9,10]$; another recent meta-analysis confirmed that IC in addition to CCRT improved progression-free survival (PFS) and overall survival (OS) [11]. However, the efficacy of adding IC to CCRT for patients with locoregionally advanced NPC remains controversial [12-14].

The addition of IC with cisplatin and fluorouracil (PF) to CCRT did not improve survival outcomes in patients with locoregionally advanced NPC, although FP has been widely used in first-line IC in these patients [15, 16]. Taxane, a new anticancer drug, in combination with cisplatin either alone (TP) or with 5-fluorouracil (TPF), improved survival in patients with locoregionally advanced head and neck squamous cell cancer [17-19]. Moreover, the addition of IC with TPF or TP to CCRT also improved survival in locoregionally advanced NPC patients [20-24].

It is unclear which IC regimen is optimal for locoregionally advanced NPC patients. In a phase II study comparing the efficacy and toxicities of IC with TPF and TP followed by CCRT in these patients, we found that TP-based IC resulted in similar survival, but fewer grade 3/4 toxicities, than TPF [25]. However, these results were considered preliminary due to the small sample size and short followup duration. We therefore performed this retrospective study to compare long-term survival outcomes after the addition of TPF or TP to CCRT in a large sample of locoregionally advanced NPC patients. To avoid the interference from covariates, we used propensity score matching (PSM) methods to establish patient pairs for comparison [26].

\section{RESULTS}

\section{Patient characteristics}

Clinical data were collected and retrospectively reviewed for a total of 650 newly-diagnosed locoregionally advanced NPC patients who were initially treated with IC followed by CCRT. Based on these data, 245 patient pairs were established using PSM. The median age of the selected subjects was 48 years (range, 18-69 years) and the male to female ratio was 2.33:1 (343 and 147, respectively). All patients completed a full course of radical IMRT and received 2-4 cycles of IC plus concurrent cisplatin for 1-2 cycles. Of the paired patients, 223 (45.5\%) patients received AC. The median total cisplatin doses in the two arms were $334 \mathrm{mg} / \mathrm{m}^{2}$ and $340 \mathrm{mg} / \mathrm{m}^{2}$, respectively. There were no statistically significant differences in age, gender, pathology, stage, or treatment factors between the TPF and TP arms. Basic patient characteristics and therapy adherence between the two arms are shown in Table 1.

\section{Survival}

The follow-up rate for all locoregionally advanced NPC patients was $93.7 \%$. At the median follow-up timepoint of 60 months (range, 8-106 months), the estimated 5-year locoregional relapse-free survival (LRRFS), distant metastasis-free survival (DMFS), progression-free survival (PFS), and overall survival (OS) rates were $96.0 \%, 94.5 \%, 91.0 \%$, and $92.0 \%$, respectively (Figure 1).

There were no statistically significant differences in 5-year LR-RFS, DMFS, PFS, or OS between the two arms (LRRFS: $95.6 \%$ vs. $96.7 \%, p=0.962$, Figure $2 \mathrm{~A}$; DMFS: $94.7 \%$ vs. $94.2 \%, p=0.897$, Figure $2 \mathrm{~B}$; PFS: $90.4 \%$ vs. $91.7 \%, p=0.750$, Figure 2 C; OS: $92.9 \%$ vs. $91.0 \%$, $p=0.600$; Figure 2D).

\section{Patterns of treatment failure}

Treatment failure occurred in 43 patients $(8.8 \%)$ by the last follow-up. In the TPF arm, 23 patients (9.4\%) experienced failure (locoregional relapse occurred in 9 patients, locoregional relapse and distant failure occurred in one patient, and distant metastases occurred in 13 patients). In the TP arm, 20 patients experienced failure (locoregional relapse occurred in 7 patients, locoregional relapse and distant failure occurred in 2 patients, and distant failure alone occurred in 11 patients). Patterns of treatment failure in NPC patients are summarized in Table 2. Median times to failure for the TPF and TP arms were 29 months (range, 6 to 65 months) and 19 months (range, 7 to 85 months), respectively.

\section{Prognostic factors}

Potential prognostic factors included patient age, gender, $\mathrm{T}$ category, $\mathrm{N}$ category, clinical stage, IC cycle, and IC regimen. We identified factors that influenced survival outcome and evaluated the prognostic role of these factors using univariate and multivariate analyses. Univariate analysis revealed that 5 -year OS was better in patients younger than 50 than in those who were 50 or older (5-year OS: $95.3 \%$ vs. $87.5 \%, p=0.003$ ), gender was associated with DMFS (5-year DMFS: $93.0 \%$ vs. $98.0 \%, p=0.028)$, and 5 -year OS was worse in stage IVA/B patients than in stage III patients (5-year OS: $86.6 \%$ vs. $96.2 \%, p<0.001)$. The results of univariate analysis of the 
Table 1: Basic demographic and tumor characteristics of 490 locoregionally advanced NPC patients

\begin{tabular}{|c|c|c|c|c|}
\hline \multirow{2}{*}{ Characteristic } & TPF regimen & TP regimen & \multirow{2}{*}{$\chi^{2}$} & \multirow{2}{*}{$p$} \\
\hline & $N=245$ & $\mathrm{~N}=\mathbf{2 4 5}$ & & \\
\hline Gender & & & 0.622 & 0.430 \\
\hline Male & $176(71.8 \%)$ & $167(68.2 \%)$ & & \\
\hline Female & $69(28.2 \%)$ & $78(31.8 \%)$ & & \\
\hline Age (years) & & & 0.008 & 0.927 \\
\hline Range & $18-68$ & $18-69$ & & \\
\hline Median & 47 & 49 & & \\
\hline$<50$ & $139(56.7 \%$ & $141(57.6 \%)$ & & \\
\hline$\geq 50$ & $106(43.3 \%)$ & $104(42.4 \%)$ & & \\
\hline WHO pathology & & & 1.095 & 0.578 \\
\hline Type I & $7(2.9 \%)$ & $4(1.6 \%)$ & & \\
\hline Type II & $10(4.1 \%)$ & $8(3.3 \%)$ & & \\
\hline Type III & $228(93.0 \%)$ & $233(95.1 \%)$ & & \\
\hline ECOG performance status & & & 1.783 & 0.182 \\
\hline 0 & $221(90.2 \%)$ & $230(93.9 \%)$ & & \\
\hline 1 & $24(9.8 \%)$ & $15(6.1 \%)$ & & \\
\hline T stage * & & & 2.736 & 0.434 \\
\hline $\mathrm{T} 1$ & $12(4.9 \%)$ & $11(4.5 \%)$ & & \\
\hline $\mathrm{T} 2$ & $24(9.8 \%)$ & $34(13.9 \%)$ & & \\
\hline $\mathrm{T} 3$ & $128(52.2 \%)$ & $114(46.5 \%)$ & & \\
\hline $\mathrm{T} 4$ & $81(33.1 \%)$ & $86(35.1 \%)$ & & \\
\hline $\mathrm{N}$ stage * & & & 2.532 & 0.470 \\
\hline No & $9(3.7 \%)$ & $6(2.4 \%)$ & & \\
\hline N1 & $69(28.2 \%)$ & $58(23.7 \%)$ & & \\
\hline $\mathrm{N} 2$ & $132(53.9 \%)$ & $148(60.4 \%)$ & & \\
\hline N3 & $35(14.2 \%)$ & $33(13.5 \%)$ & & \\
\hline Clinical stage ${ }^{*}$ & & & 0.214 & 0.899 \\
\hline III & $133(54.3 \%)$ & $132(53.9 \%)$ & & \\
\hline IVA & $77(31.4 \%)$ & $80(32.7 \%)$ & & \\
\hline IVB & $35(14.3 \%)$ & $33(13.4 \%)$ & & \\
\hline IC cycle & & & 2.107 & 0.147 \\
\hline 2 & $142(59.2 \%)$ & $125(51.0 \%)$ & & \\
\hline $3-4$ & $103(40.8 \%)$ & $120(49.0 \%)$ & & \\
\hline $\mathrm{AC}$ & & & 0.296 & 0.586 \\
\hline No & $137(55.9 \%)$ & $130(53.1 \%)$ & & \\
\hline Yes & $108(44.1 \%)$ & $115(46.9 \%)$ & & \\
\hline
\end{tabular}

Abbreviations: WHO, World Health Organization; ECOG, Eastern Cooperative Oncology Group; IC, induction chemotherapy; AC, adjuvant chemotherapy; * The $7^{\text {th }}$ AJCC/UICC staging system. 
490 locoregionally advanced NPC patients are shown in Table 3. Multivariate analysis indicated that age was an independent predictor of LRRFS ( $p=0.029)$. IC regimen was not an independent prognostic factor for any of the survival outcomes (Table 4).

\section{Safety and toxicity}

Hematologic and non-hematologic toxicities were the most common side effects observed after treatment. Incidences of acute toxicities resulting from IC and CCRT are listed in Table 5. Incidence of grade 3 or higher leukocytopenia and neutropenia was higher in TPF arm patients than in TP arm patients during IC treatment (58.4\% vs. $20.4 \%, p<0.001 ; 66.1 \%$ vs. $22.4 \%, p<0.001$ ). Additionally, more patients in the TPF arm suffered diarrhea than did those in the TP arm (33.1\% vs. $7.8 \%$, $p=0.033)$. There were no other significant differences in toxicities between the two arms. In addition, no statistically significant differences in rates of hematologic and non-hematologic complications were observed between the two arms during CCRT.
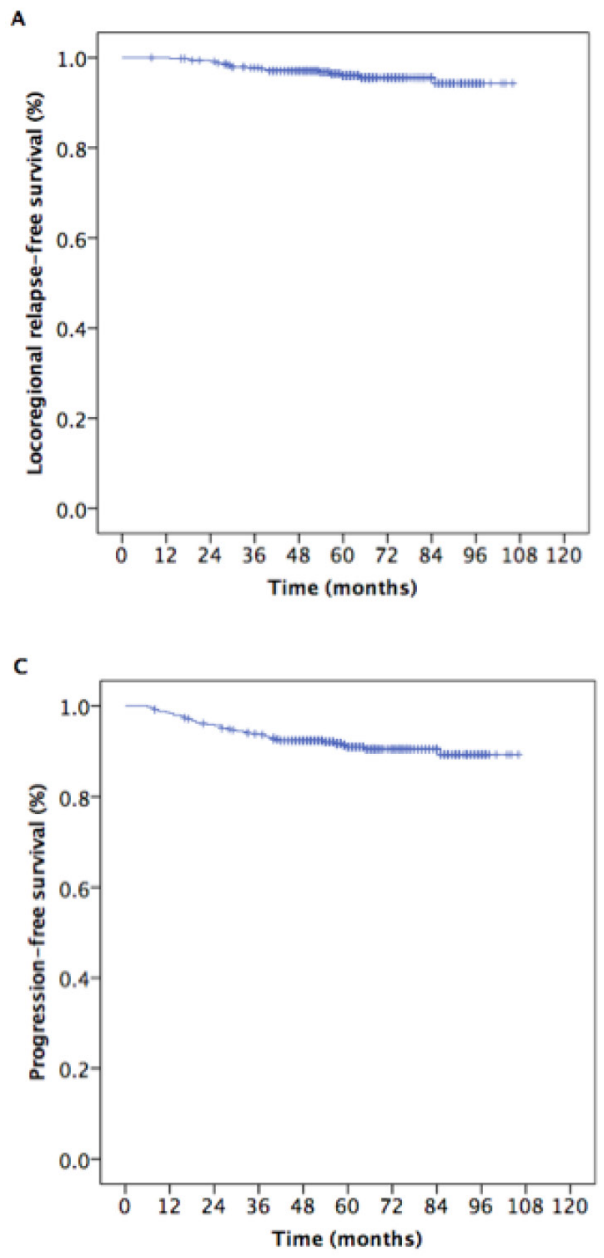

\section{DISCUSSION}

Few studies have compared the efficacy and safety of TPF and TP in patients with locoregionally advanced NPC. To the best of our knowledge, this is the first study to compare long-term survival outcomes and toxicities of TPF and TP in a large sample size of locoregionally advanced NPC patients. We found that 5-year LRRFS (95.6\% vs. 96.7\%), DMFS (94.7\% vs. 94.2\%), PFS (90.4\% vs. $91.7 \%)$, and OS (92.9\% vs. 91\%) rates did not differ between the two treatment arms. However, incidences of leucopenia, neutropenia, and diarrhea were lower in TP arm patients than in TPF arm patients. These results indicate that TP-based IC has similar efficacy to, but is associated with fewer grade $3 / 4$ acute toxicities than, TPF treatment; the omission of 5-fluorouracil from IC therefore did not affect survival outcomes.

We also examined the prognostic value of various factors, including patient age, gender, $\mathrm{T}$ category, $\mathrm{N}$ Category, clinical stage, AC, IC cycle, and IC regimen. Gender was an independent prognostic factor of LRRFS, while age and clinical stage were independent predictors
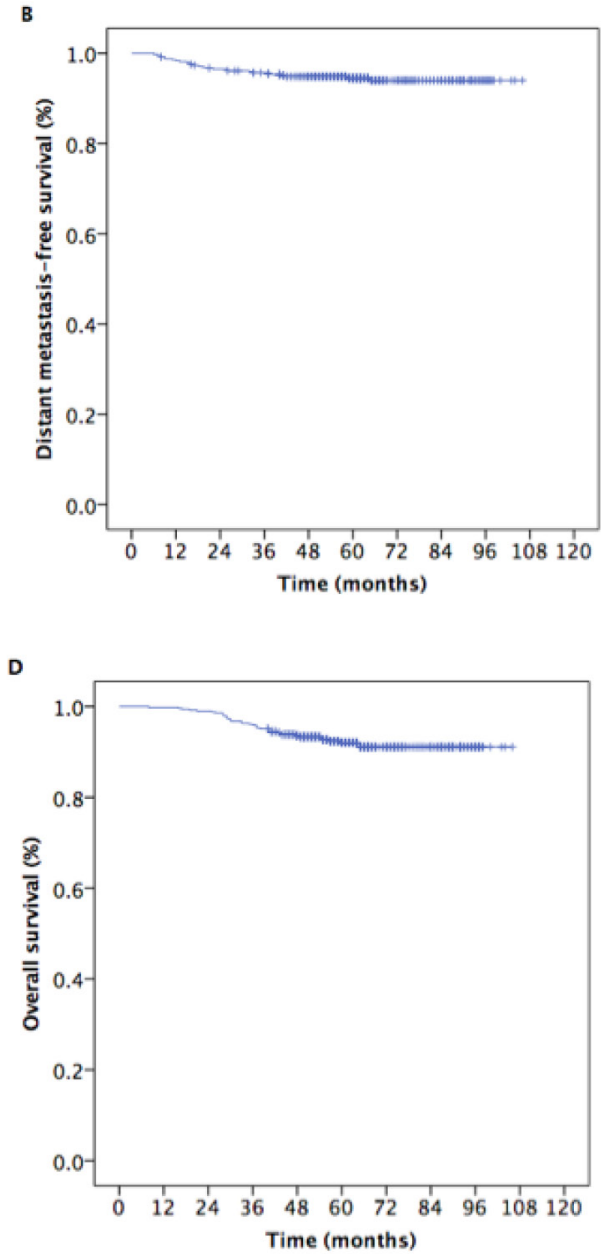

Figure 1: Kaplan-Meier estimates of survival in 490 patients with locoregionally advanced nasopharyngeal carcinoma. 
of OS; in contrast, IC regimen was not an independent prognostic factor for any of the survival outcome measures.

Survival improvements following the addition of docetaxel to IC with cisplatin and 5-fluorouracil were first described in locoregionally advanced head and neck cancer [17-19]. An IC regimen that included docetaxel also improved survival in patients with locoregionally advanced NPC [20-25]. In a randomized phase III study, 3 cycles of TPF IC followed by CCRT improved 3-year failure-free survival rates compared to CCRT alone $(80 \%$ vs. $72 \%$ ) [20]. Kong et al. reported that the addition of TPF IC to CCRT was associated with prolonged survival, with a 3-year LRFS, DMFS, PFS, and OS rates of 93.9\%, $90.5 \%, 78.2 \%$, and $94.8 \%$, respectively, in locoregionally advanced NPC patients [21]. Kawahira et. al. showed that TPF IC before CCRT reduced distant metastasis in patients with nodal stage N2-3 disease [27]. However, Qu et al. found that the addition of TPF IC to CCRT did not improve 5 -year OS (78.3\% vs. $82.7 \%)$ or PFS (72.5\% vs. $68.2 \%)$ [28].
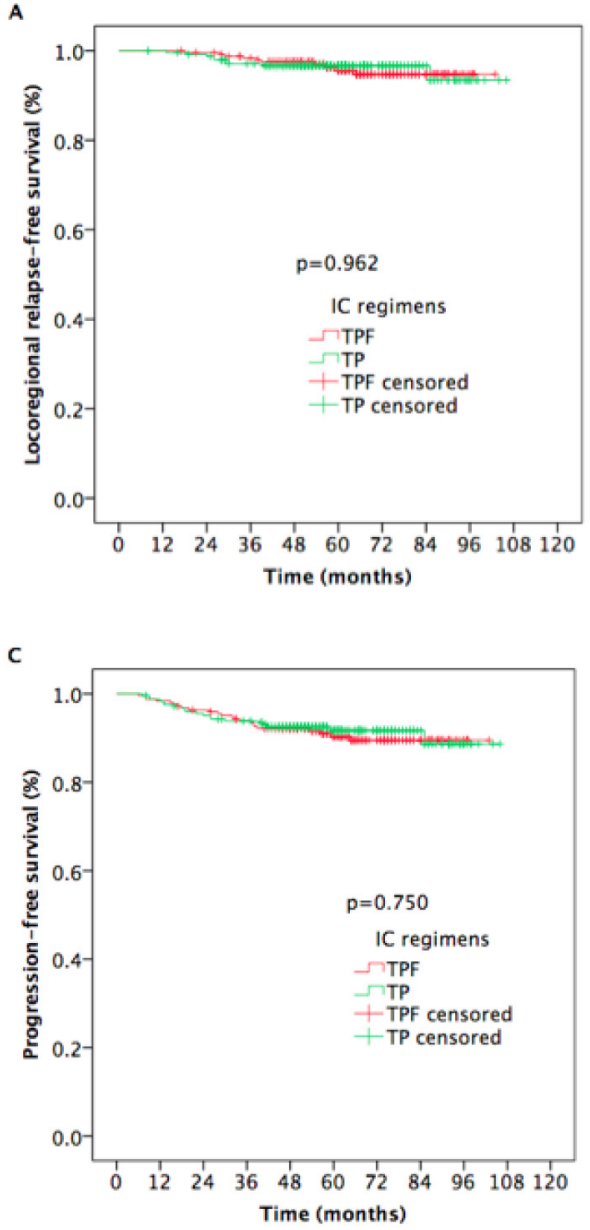

Hassan et al. demonstrated that TP IC before CCRT provided good local control with an acceptable toxicity profile in locoregionally advanced NPC patients [22]. In a randomized phase II trial, Hui et al. observed that adding 2 cycles of TP IC to CCRT increased 3-year OS compared to CCRT alone (94.1\% vs. 67.7\%) [23]. In another phase II trial by Zhong et al., the addition of TP IC to CCRT resulted in 3-year OS and PFS rates of $94.1 \%$ and $72.7 \%$, respectively [24].

While first-line IC regimens consisting of docetaxel plus cisplatin with or without 5-fluorouracil have resulted in excellent survival outcomes in locoregionally advanced NPC patients, few studies have compared the efficacy and toxicities of TP and TPF before CCRT in these patients. In our previous phase II study that examined the efficacy and tolerability of adding TPF or TP to concurrent chemotherapy and IMRT in locoregionally advanced NPC patients [25], both IC regimens resulted in similar survival outcomes, but the sample size was small and the follow-up time was short. We therefore conducted this observational study to investigate long-term survival outcomes in a
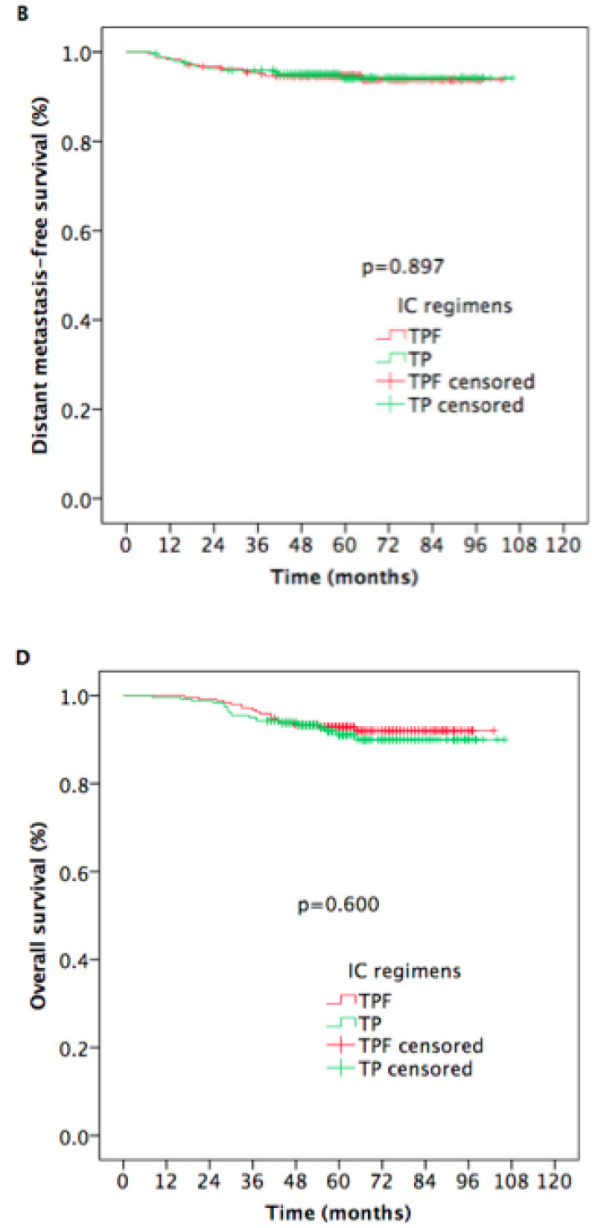

Figure 2: Kaplan-Meier estimates of survival outcomes in TPF and TP arm nasopharyngeal carcinoma patients. 
Table 2: Patterns of treatment failure

\begin{tabular}{lccc}
\hline \multirow{2}{*}{ Failure mode } & TPF & TP & $\boldsymbol{p}$ \\
\cline { 2 - 4 } & $\mathbf{N = 2 4 5}$ & $\mathbf{N = 2 4 5}$ & 0.857 \\
Locoregional & 9 & 7 & 2 \\
Locoregional and distant & 1 & 11 \\
Distant & 13 & 225 \\
No failure & 222 & & \\
\hline
\end{tabular}

Table 3: Prognostic factors in 490 NPC patients identified using univariate analysis

\begin{tabular}{|c|c|c|c|c|c|c|c|c|c|}
\hline Characteristic & $\mathbf{N}$ & LRRFS (\%) & $p$ & $\begin{array}{c}\text { DMFS } \\
(\%)\end{array}$ & $p$ & PFS (\%) & $p$ & OS (\%) & $p$ \\
\hline Age & & & 0.050 & & 0.340 & & 0.761 & & 0.003 \\
\hline$<50$ & 280 & 96.8 & & 93.3 & & 90.5 & & 95.3 & \\
\hline$\geq 50$ & 210 & 95.1 & & 86.2 & & 91.8 & & 87.5 & \\
\hline Gender & & & 0.517 & & 0.028 & & 0.175 & & 0.360 \\
\hline Male & 94 & 96.4 & & 93.0 & & 89.7 & & 91.3 & \\
\hline Female & 38 & 95.2 & & 98.0 & & 93.9 & & 93.7 & \\
\hline T stage & & & 0.306 & & 0.820 & & 0.497 & & 0.867 \\
\hline $\mathrm{T} 1-2$ & 82 & 94.6 & & 95.1 & & 89.9 & & 92.3 & \\
\hline T3-4 & 408 & 96.3 & & 94.3 & & 91.2 & & 92.0 & \\
\hline N stage & & & 0.788 & & 0.211 & & 0.373 & & 0.136 \\
\hline N0-1 & 142 & 96.4 & & 96.4 & & 92.9 & & 94.5 & \\
\hline $\mathrm{N} 2-3$ & 348 & 95.9 & & 93.7 & & 90.2 & & 91.0 & \\
\hline Clinical stage & & & 0.370 & & 0.166 & & 0.073 & & $<0.001$ \\
\hline III & 279 & 96.6 & & 96.1 & & 93.1 & & 96.2 & \\
\hline IVA/B & 211 & 95.2 & & 92.3 & & 88.2 & & 86.6 & \\
\hline IC cycle & & & 0.302 & & 0.120 & & 0.520 & & 0.811 \\
\hline 2 & 270 & 95.3 & & 95.9 & & 92.0 & & 91.3 & \\
\hline $3-4$ & 220 & 96.8 & & 92.7 & & 89.6 & & 93.0 & \\
\hline IC regimen & & & 0.199 & & 0.554 & & 0.835 & & 0.434 \\
\hline $\mathrm{TPF}$ & 57 & 96.4 & & 87.7 & & 86.0 & & 94.7 & \\
\hline $\mathrm{TP}$ & 75 & 90.3 & & 91.9 & & 85.2 & & 92.0 & \\
\hline $\mathrm{AC}$ & & & 0.101 & & 0.767 & & 0.255 & & 0.552 \\
\hline No & 267 & 97.4 & & 94.8 & & 92.3 & & 93.0 & \\
\hline Yes & 223 & 94.5 & & 94.1 & & 89.6 & & 90.8 & \\
\hline
\end{tabular}

Abbreviations: LRRFS, locoregional relapse-free survival; DMFS, distant metastases-free survival; PFS, progression-free survival; OS, overall survival; IC, induction chemotherapy; TP, docetaxel/cisplatin; TPF, docetaxel/cisplatin/fluorouracil. 
Table 4: Summary of multivariate analyses of prognostic factors in 490 NPC patients

\begin{tabular}{|c|c|c|c|c|}
\hline Endpoint & Factor & HR & $95 \% \mathrm{CI}$ & $p$ \\
\hline \multirow[t]{7}{*}{ LRRFS } & Age: $<50$ years vs. $\geq 50$ years & 0.345 & $0.133-0.896$ & 0.029 \\
\hline & Gender: male vs. female & 0.581 & $0.224-1.503$ & 0.263 \\
\hline & T category: T1-2 vs. T3-4 & 1.760 & $0.586-5.291$ & 0.314 \\
\hline & N category: N0-1 vs. N2-3 & 0.975 & $0.323-2.942$ & 0.965 \\
\hline & AC: no vs. yes & 0.356 & $0.110-1.152$ & 0.085 \\
\hline & IC cycle: 2 vs. $3-4$ & 1.068 & $0.311-3.661$ & 0.917 \\
\hline & IC regimen: TPF vs. TP & 1.413 & $0.511-3.903$ & 0.505 \\
\hline \multirow[t]{7}{*}{ DMFS } & Age: $<50$ years vs. $\geq 50$ years & 1.473 & $0.654-3.313$ & 0.350 \\
\hline & Gender: male vs. female & 3.346 & $0.998-11.216$ & 0.050 \\
\hline & T category: T1-2 vs. T3-4 & 1.065 & $0.379-2.994$ & 0.905 \\
\hline & N category: N0-1 vs. N2-3 & 0.588 & $0.215-1.606$ & 0.300 \\
\hline & AC: no vs. yes & 0.677 & $0.252-1.814$ & 0.437 \\
\hline & IC cycle: 2 vs. $3-4$ & 0.387 & $0.148-1.016$ & 0.054 \\
\hline & IC regimen: TPF vs. TP & 0.947 & $0.349-2.572$ & 0.915 \\
\hline \multirow[t]{7}{*}{ PFS } & Age: $<50$ years vs. $\geq 50$ years & 0.874 & $0.473-1.613$ & 0.666 \\
\hline & Gender: male vs. female & 1.499 & $0.713-3.155$ & 0.286 \\
\hline & T category: T1-2 vs. T3-4 & 1.245 & $0.570-2.717$ & 0.583 \\
\hline & N category: N0-1 vs. N2-3 & 0.262 & $0.362-1.601$ & 0.473 \\
\hline & AC: no vs. yes & 0.490 & $0.224-1.073$ & 0.074 \\
\hline & IC cycle: 2 vs. $3-4$ & 0.569 & $0.263-1.230$ & 0.151 \\
\hline & IC regimen: TPF vs. TP & 1.247 & $0.595-2.613$ & 0.559 \\
\hline \multirow[t]{7}{*}{ OS } & Age: $<50$ years vs. $\geq 50$ years & 0.353 & $0.178-0.698$ & 0.003 \\
\hline & Gender: male vs. female & 1.156 & $0.542-2.468$ & 0.707 \\
\hline & T category: T1-2 vs. T3-4 & 0.919 & $0.392-2.156$ & 0.846 \\
\hline & N category: N0-1 vs. N2-3 & 0.506 & $0.217-1.182$ & 0.115 \\
\hline & AC: no vs. yes & 0.824 & $0.373-1.820$ & 0.632 \\
\hline & IC cycle: 2 vs. $3-4$ & 0.778 & $0.337-1.796$ & 0.557 \\
\hline & IC regimen: TPF vs. TP & 0.943 & $0.430-2.069$ & 0.884 \\
\hline
\end{tabular}

Abbreviations: LRRFS, locoregional relapse-free survival; DMFS, distant metastasis-free survival; PFS, progression-free survival; OS, overall survival; IC, induction chemotherapy; AC, adjuvant chemotherapy; TP, docetaxel/cisplatin; TPF, docetaxel/cisplatin/fluorouracil.

large group of patients who received either TPF or TP. We observed that long-term survival outcomes were similar among patients in the TP and TPF arms, indicating that omission of 5-fluorouracil from TPF IC did not affect survival.

Factors that are often associated with prognostic value include age, gender, clinical stage, IC cycle, and IC regimen. Here, univariate analysis revealed that age, gender, and clinical stage impacted survival outcomes, while age and gender were identified as independent prognostic factors in multivariate analysis. However, neither univariate nor multivariate analysis indicated that IC regimen affected any of the survival outcomes. This result is particularly informative because the 490 patients examined in this study were paired in our analysis; thus, these findings strongly suggest that TPF and TP IC before CCRT result in similar survival outcomes. 
Table 5: Toxicity from IC and CCRT between the two arms

\begin{tabular}{|c|c|c|c|c|c|c|c|c|c|c|}
\hline \multirow{3}{*}{$\begin{array}{l}\text { Adverse event } \\
\text { (toxicity grade) }\end{array}$} & \multicolumn{5}{|c|}{ IC } & \multicolumn{5}{|c|}{ CCRT } \\
\hline & \multicolumn{2}{|c|}{ TPF arm } & \multicolumn{2}{|c|}{ TP arm } & \multirow{2}{*}{$p$} & \multicolumn{2}{|c|}{ TPF arm } & \multicolumn{2}{|c|}{ TP arm } & \multirow{2}{*}{$p$} \\
\hline & $1-2$ & $3-4$ & $1-2$ & $3-4$ & & $1-2$ & $3-4$ & $1-2$ & $3-4$ & \\
\hline \multicolumn{11}{|l|}{ Hematologic } \\
\hline Leukocytopenia & 99 & 143 & 172 & 50 & $<0.001$ & 163 & 22 & 154 & 46 & 0.516 \\
\hline Neutropenia & 60 & 162 & 145 & 55 & $<0.001$ & 142 & 43 & 138 & 33 & 0502 \\
\hline Anemia & 73 & 4 & 87 & 7 & 0.157 & 60 & 0 & 79 & 0 & 0.691 \\
\hline Thrombocytopenia & 48 & 4 & 49 & 3 & 0.128 & 51 & 13 & 36 & 7 & 0.975 \\
\hline Liver function & 154 & 4 & 105 & 2 & 0.520 & 47 & 0 & 43 & 0 & 0.055 \\
\hline Renal function & 7 & 0 & 7 & 0 & 0.254 & 13 & 0 & 11 & 0 & 0.277 \\
\hline \multicolumn{11}{|l|}{ Non-hematologic } \\
\hline Mucositis & 30 & 0 & 25 & 0 & 0.874 & 232 & 13 & 232 & 13 & 1.0 \\
\hline Dermatitis & 13 & 0 & 8 & 0 & 0.559 & 239 & 6 & 241 & 4 & 0.518 \\
\hline Diarrhea & 77 & 4 & 19 & 0 & 0.033 & 22 & 4 & 17 & 2 & 0.770 \\
\hline Nausea/vomiting & 47 & 4 & 35 & 4 & 0.937 & 34 & 1 & 33 & 3 & 0.099 \\
\hline
\end{tabular}

Abbreviations: IC, induction chemotherapy; CCRT, concurrent chemoradiotherapy.

Hematologic and non-hematologic toxicities were the most commonly observed side effects in patients during the treatment period. Incidences of grade 3 or higher leukocytopenia and neutropenia lower in patients who received TP than in those who received TPF $(20.4 \%$ vs. $58.4 \%$ and $22.4 \%$ vs. $66.1 \%$ ). The incidences of hematologic toxicities observed after TPF treatment in this study were similar to those in previous studies (ranging from 55-83\%) [17, 18, 21, 29]. All patients in this study received prophylaxis leukocyte therapy in the form of recombinant granulocyte colony-stimulating factor (GCSF), which allowed those who experienced grade 3/4 leukocytopenia and neutropenia during IC treatment to continue with chemotherapy as initially scheduled. Non-hematologic side effects, such as mucositis, dermatitis, diarrhea, and nausea/vomiting, were mild to moderate. The incidence of diarrhea was lower in TP arm patients than in TPF arm patients $(7.8 \%$ vs. $33.1 \%$ ); incidences of the other complications did not differ between two arms.

Some limitations of this study should be considered when interpreting the results. First, this retrospective study was conducted at single center. Second, only acute treatment-associated toxicities were evaluated; later-stage complications were not examined. Third, acute toxicities were assessed based only on information provided in medical record. Finally, as in many retrospective studies, data was incomplete for many patients. Our results should therefore be regarded as preliminary, and additional prospective clinical trials in larger patient populations should be conducted to confirm these findings.

In conclusion, we found that the addition of either TP or TPF-based IC to IMRT with concurrent chemotherapy resulted in similar improvements in survival, including LRRFS, DMFS, PFS, and OS, in locoregionally advanced NPC patients, while TP IC was associated with lower incidences of grade $3 / 4$ acute toxicities. Thus, omission of 5-fluorouracil from TPF-based IC did not affect survival outcomes. However, additional randomized, controlled, multicenter phase III clinical trials are needed to assess the efficacy and toxicity of TP IC regimens.

\section{MATERIALS AND METHODS}

\section{Patients}

The patients enrolled in this study were hospitalized in the Department of Radiation Oncology, Zhejiang Cancer Hospital between May 2008 and April 2014. Eligible patients met the following criteria: (i) histologically confirmed locoregionally advanced NPC, (ii) Eastern Cooperative Oncology Group performance status $\leq 1$, (iii) completion of radical IMRT, (iv) received IC before CCRT with or without AC, and (v) no previous anti-cancer treatment. Ultimately, data from 490 of the 650 patients initially examined were included in the study.

The exclusion criteria were as follows: patients who were 70 years old or older; received RT, chemotherapy 
or surgery for tumors; had distant metastases before treatment; were pregnant; had a history of other malignancy; had severe comorbidities. This retrospective study was approved by the Medical Ethics Committee and the institutional reviewed board of Zhejiang Cancer Hospital. All the patients provided informed consent.

Of the 650 patients initially enrolled, 252 were treated with TP-based IC before CCRT and 398 were treated with TPF-based IC before CCRT. Patients in the two arms were paired using PSM based on gender, age, pathological type, $\mathrm{T}$ stage, $\mathrm{N}$ stage, clinical stage, ECOG, and IC cycle. 245 patient pairs were examined.

\section{Baseline examinations}

Patients underwent pretreatment evaluations that included complete histories, physical examinations, hematology and biochemistry profiles, chest radiographs, sonography of the abdomen, bone scans, magnetic response images of the nasopharynx, and nasopharyngoscopies. All patients were staged according to the 2010 American Joint Committee on Cancer staging system. Tumor histology was classified per the World Health Organization classification.

\section{Intensity-modulated radiotherapy}

All patients underwent radical IMRT with simultaneous integrated boost technique using $6 \mathrm{MV}$ photons within 2-3 weeks after IC. Target volumes of NPC during IMRT treatment were delineated as described previously [25, 30-33]. Briefly, gross tumor volumes (GTV) of the primary tumor (GVTnx) and metastatic lymph nodes (GTVnd) were delineated according to preand post-IC MR images, respectively. The nasopharynx clinical target volume (CTVnx) was defined as GTVnx plus a 7-mm margin that encompassed the nasopharyngeal mucosa plus $5 \mathrm{~mm}$ submucosal volume. The highrisk clinical target volume (CTV1) included the entire nasopharyngeal cavity, the anterior one- to two-thirds of the clivus, the skull base, the pterygoid plates, the parapharyngeal space, the inferior sphenoid sinus, the posterior one-quarter to one-third of the nasal cavity, the maxillary sinus, and any lymph nodes in drainage pathways containing metastatic lymph nodes. The low-risk clinical target volume (CTV2) included levels IV and Vb without metastatic cervical lymph nodes.

The PTV was constructed automatically based on each volume with an additional 3-mm margin in three dimensions to account for set-up variability. None of the PTVs, including PGTVnx, PTVnx, PTV1, and PTV2, were delineated outside of the skin surface. Critical normal structures, including the brainstem, spinal cord, parotid glands, optic nerves, chiasm, lens, eyeballs, temporal lobes, temporomandibular joints, mandible, and hypophysis, were contoured and set as OARs during optimization.
The prescribed radiation dose was 69 or 72 Gy to PGTVnx, 66-70 Gy to PGTVnd, 62-66 Gy to PTVnx, 6063 Gy to PTV1, and 51-54 Gy to PTV2, delivered in 30 or 33 fractions. Radiation was delivered once daily and at five fractions per week over 6-6.5 weeks for IMRT planning. The dose to OAR was limited based on the RTOG 0225 protocol.

\section{Chemotherapy}

All patients were given two to four cycles of platinum-based induction chemotherapy three times per week. TPF (docetaxel $60 \mathrm{mg} / \mathrm{m}^{2} /$ day on day 1 , cisplatin $25 \mathrm{mg} / \mathrm{m}^{2} /$ day on days $1-3$, and 5 -fluorouracil $500 \mathrm{mg} / \mathrm{m}^{2} /$ day on days 1-3) or TP (docetaxel $60 \mathrm{mg} / \mathrm{m}^{2} /$ day on day 1 , cisplatin $25 \mathrm{mg} / \mathrm{m}^{2} /$ day on days $1-3$ ) IC regimens were used.

The patients in this study also underwent concurrent chemotherapy with cisplatin $\left(80 \mathrm{mg} / \mathrm{m}^{2}\right)$ divided across 3 days and received adjuvant chemotherapy with FP (cisplatin $25 \mathrm{mg} / \mathrm{m}^{2} /$ day and 5 -fluorouracil $500 \mathrm{mg} / \mathrm{m}^{2} /$ day on days 1-3) within 3-4 weeks after RT.

\section{Patient evaluation and follow-up}

Tumor responses were assessed based on MRI and nasopharynx fiberscope according to the Response Evaluation Criteria for Solid Tumors on three occasions: after the completion of induction chemotherapy, at the end of IMRT, and 3 months after radiation. Adverse effects resulting from systemic chemotherapy were graded using the National Cancer Institute Common Toxicity Criteria (NCI CTCAE, version 3.0), whereas RT-induced toxicities were scored according to the Acute and Late Radiation Morbidity Scoring Criteria of the Radiation Therapy Oncology Group (RTOG).

All the subjects underwent weekly examinations for treatment response and toxicities during radiation therapy. Patient followed-ups were conducted every 3 months for the first 2 years, every 6 months from the third to the fifth year, and annually thereafter. Each follow-up included careful examination of the nasopharynx and neck nodes by an experienced doctor, MRI scan of the nasopharynx, nasopharynx fiberscope, chest computed tomography radiograph, and ultrasound of abdomen 3 months after the completion of RT and every 6-12 months thereafter. Additional examinations were performed when indicated to evaluate local relapse or distant metastasis.

\section{Statistical analysis}

The endpoints examined included LRRFS, DMFS, PFS, OS, and acute toxicities after IC and CCRT. OS was calculated from the date of enrollment in the study to the date of death or the last follow-up. LRRFS, DMFS, and PFS were calculated from the date of enrollment to the date of locoregional relapse, occurrence of distant metastasis, and disease progression, respectively, or the date of the last 
follow-up. After recurrence or metastasis, patients received salvage therapy at the discretion of their physicians.

Descriptive statistics were used to compare patient characteristics, treatment adherence, and patterns of failure between the two arms. Independent sample nonparametric tests were used to compare acute toxicity between the two arms. Survival curves were generated using the Kaplan-Meier method and compared using logrank tests. Multivariate analysis was performed using Cox regression models to identify significant prognostic factors. Hazard ratios (HRs) and 95\% confidence intervals (CIs) were calculated for each prognostic factor. IBM SPSS Statistics version 19.0 was used for all data analysis, and $p<0.05$ was considered statistically significant.

\section{CONFLICTS OF INTEREST}

The authors declare that there are no conflicts of interest.

\section{FUNDING}

This study was supported by grants from the Medical Science Foundation of Zhejiang Health Bureau (No. 2013KYB033, No. 2009B026, No. 2006A016, No. 2005B012, and No. 2004B014) and the National Natural Science Foundation of China (No. 81502646, No. 81502647).

\section{REFERENCES}

1. Tang LL, Chen WQ, Xue WQ, He YQ, Zheng RS, Zeng YX, Jia WH. Global trends in incidence and mortality of nasopharyngeal carcinoma. Cancer Lett. 2016; 374: 22-30.

2. Chen L, Mao YP, Xie FY, Liu LZ, Sun Y, Tian L, Tang LL, Lin AH, Li L, Ma J. The seventh edition of UICC/ AJCC staging system for nasopharyngeal carcinoma is prognostically useful for patients treated with intensitymodulated radiotherapy from an endemic area in China. Radiother Oncol. 2012; 104: 331-337.

3. Wee J. Nasopharyngeal carcinoma: a promising future. Lancet Oncol. 2012; 13: 116-118.

4. Lai SZ, Li WF, Chen L, Luo W, Chen YY, Liu LZ, Sun Y, Lin AH, Liu MZ, Ma J. How does intensity modulated radiotherapy versus conventional twodimensional radiotherapy influence the treatment results in nasopharyngeal carcinoma patients? Int J Radiat Oncol Biol Phys. 2011; 80: 661-668.

5. Al-Sarraf M, Reddy MS. Nasopharyngeal carcinoma. Curr Treat Options Oncol. 2002; 3: 21-32.

6. Al-Sarraf M, LeBlanc M, Giri PG, Fu KK, Cooper J, Vuong T, Forastiere AA, Adams G, Sakr WA, Schuller DE, Ensley JF. Chemoradiotherapy versus radiotherapy in patients with advanced nasopharyngeal cancer: phase III randomized Intergroup study 0099. J Clin Oncol. 1998; 16: 1310-1317.
7. Lee AW, Tung SY, Chua DT, Ngan RK, Chappell R, Tung R, Siu L, Ng WT, Sze WK, Au GK, Law SC, O'Sullivan $\mathrm{B}$, Yau TK, et al. Randomized trial of radiotherapy plus concurrent-adjuvant chemotherapy vs radiotherapy alone for regionally advanced nasopharyngeal carcinoma. J Natl Cancer Inst. 2010; 102: 1188-1198.

8. Baujat B, Audry H, Bourhis J, Chan AT, Onat H, Chua DT, Kwong DL, Al-Sarraf M, Chi KH, Hareyama M, Leung SF, Thephamongkhol K, Pignon JP; MAC-NPC Collaborative Group. Chemotherapy in locally advanced nasopharyngeal carcinoma: an individual patient data meta-analysis of eight randomized trials and 1753 patients. Int J Radiat Oncol Biol Phys. 2006; 64: 47-56.

9. OuYang PY, Xie C, Mao YP, Zhang Y, Liang XX, Su Z, Liu Q, Xie FY. Significant efficacies of neoadjuvant chemotherapy and adjuvant chemotherapy for nasopharyngeal carcinoma by meta-analysis of published literature-based randomized, control trials. Ann Oncol. 2013; 24: 2136-2146.

10. Chen YP, Guo R, Liu N, Liu X, Mao YP, Tang LL, Zhou GQ, Lin AH, Sun Y, Ma J. Efficacy of the additional neoadjuvant chemotherapy to concurrent chemoradiotherapy for patients with locoregionally advanced nasopharyngeal carcinoma: a Bayesian network meta-analysis of randomized controlled trials. J Cancer. 2015; 6: 883-892.

11. Wang MM, Tian HM, Li G, Ge T, Liu Y, Cui J, Han F. Significant benefits of adding neoadjuvant chemotherapy before chemoradiotherapy for locoregionally advanced nasopharyngeal carcinoma: a meta-analysis of randomized controlled trials. Oncotarget. 2016; 7: 48375-48390. https:// doi.org/10.18632/oncotarget.10237.

12. Hui EP, Ma BB, Leung SF, King AD, Mo F, Kam MK, Yu BK, Chiu SK, Kwan WH, Ho R, Chan I, Ahuja AT, Zee BC, Chan AT. Randomized phase II trial of concurrent cisplatinradiotherapy with or without neoadjuvant docetaxel and cisplatin in advanced nasopharyngeal carcinoma. J Clin Oncol. 2009; 27: 242-249.

13. Fountzilas G, Cluleanu E, Bobos M, Kalogera-Fountzila A, Eleftheraki AG, Karayannopoulou G, Zaramboukas T, Nikolaou A, Markou K, Resiga L, Dionysopoulos D, Samantas E, Athanassiou $\mathrm{H}$, et al. Induction chemotherapy followed by concomitant radiotherapy and weekly cisplatin versus the same concomitant chemoradiotherapy in patents with nasopharyngeal carcinoma: a randomized phase II study conducted by the Hellenic Cooperative Oncology Group (HeCOG) with biomarker evaluation. Ann Oncol. 2012; 23: 427-435.

14. Huang PY, Cao KJ, Guo X, Mo HY, Guo L, Xiang YQ, Deng MQ, Qiu F, Cao SM, Guo Y, Zhang L, Li NW, Sun R, et al. A randomized trial of induction chemotherapy plus concurrent chemoradiotherapy versus induction chemotherapy plus radiotherapy for locoregionally advanced nasopharyngeal carcinoma. Oral Oncol. 2012; 48: 1034-1044.

15. Baujat B, Audry H, Bourhis J, Chan AT, Onat H, Chua DT, Kwong DL, Al-Sarraf M, Chi KH, Hareyama M, Leung SF, Thephamongkhol K, Pignon JP, et al. Chemotherapy in 
locally advanced nasopharyngeal carcinoma: an individual patient data meta-analysis of eight randomized trials and 1753 patients. Int J Radiat Oncol Biol Phys. 2006; 64: 47-56.

16. Blanchard P, Lee A, Marguet S, Leclercq J, Ng WT, Ma J, Chan AT, Huang PY, Benhamou E, Zhu G, Chua DT, Chen Y, Mai HQ, et al. Chemotherapy and radiotherapy in nasopharyngeal carcinoma: an update of the MAC-NPC meta-analysis. Lancet Oncol. 2015; 16: 645-655.

17. Vermorken JB, Remenar E, van Herpen C, Gorlia T, Mesia R, Degardin M, Stewart JS, Jelic S, Betka J, Preiss JH, van den Weyngaert D, Awada A, Cupissol D, et al. Cisplatin, fluorouracil, and docetaxel in unresectable head and neck cancer. N Engl J Med. 2007; 357: 1695-1704.

18. Posner MR, Hershock DM, Blajman CR, Mickiewicz E, Winquist E, Gorbounova V, Tjulandin S, Shin DM, Cullen K, Ervin TJ, Murphy BA, Raez LE, Cohen RB, et al. Cisplatin and fluorouracil alone or with docetaxel in head and neck cancer. N Engl J Med. 2007; 357: 1705-1715.

19. Pointreau Y, Garaud P, Chapet S, Sire C, Tuchais C, Tortochaux J, Faivre S, Guerrif S, Alfonsi M, Calais G. Randomized trial of induction chemotherapy with cisplatin and 5-fluorouracil with or without docetaxel for larynx preservation. J Natl Cancer Inst. 2009; 101: 498-506.

20. Sun Y, Li WF, Chen NY, Zhang N, Hu GQ, Xie FY, Sun Y, Chen XY, Li JG, Zhu XD, Hu CS, Xu XY, Chen $\mathrm{YY}$, et al. Induction chemotherapy plus concurrent chemotherapy versus concurrent chemoradiotheray alone in locoregionally advanced nasopharyngeal carcinoma: a phase 3, multicentre, randomized controlled trial. Lancet Oncol. 2016; 12: 1509-1520.

21. Kong L, Zhang YW, Hu CS, Guo Y, Lu JJ. Effects of induction doctetaxel, platinum, and fluorouracil chemotherapy in patients with stage III or IVA/B nasopharyngeal cancer treated with concurrent chemoradiation therapy: final results of 2 parallel phase clinical trial. Cancer. 2017; 123: 22582267. https://doi.org/10.1002/cncr.30566.

22. Hassan E, Galai K, Esmat E. Neoadjuvant docetaxel and cisplatin followed by concurrent cisplatin with radiation therapy in treatment of locally advanced nasopharyngeal carcinoma. Gulf J Oncolog. 2008; 10: 46-53.

23. Hui EP, Ma BB, Leung SF, King AD, Mo F, Kam MK, Yu BK, Chiu SK, Kwan WH, Ho R, Chan I, Ahuja AT, Zee $\mathrm{BC}$, et al. Randomized phase II trial of concurrent cisplatinradiotherapy with or without neoadjuvant docetaxel and cisplatin in advanced nasopharyngeal carcinoma. J Clin Oncol. 2009; 27: 242-249.

24. Zhong YH, Dai J, Wang XY, Xie CH, Chen G, Zeng L, Zhou YF. Phase II trial of neoadjuvant docetaxel and cisplatin followed by intensity-modulated radiotherapy with concurrent cisplatin in locally advanced nasopharyngeal carcinoma. Cancer Chemother Pharmacol. 2013; 71: 1577-1583.

25. Wang F, Jiang C, Wang L, Yan F, Ye Z, Sun Q, Liu T, Xu M, Wu P, Long B, Rihito A, Masoto S, Fu Z. Addition of 5-fluorouracil to first-line induction chemotherapy with docetaxel and cisplatin before concurrent chemoradiotherapy does not improve survival in locoregionally advanced nasopharyngeal carcinoma. Oncotarget. 2017; 8: 9115091161. https://doi.org/10.18632/oncotarget.20017.

26. Austin PC. The relative ability of different propensity score methods to balance measured covariates between treated and untreated subjects in observational studies. Med Decis Making. 2009; 29: 661-677.

27. Kawahira M, Yokota T, Hamauchi S, Onozawa Y, Ogawa H, Onoe T, Kamijo T, Lida Y, Nishimura T, Onitsuka T, Yasui H. Survival benefit of adding docetaxel, cisplatin and 5-fluorouracil induction chemotherapy to concurrent chemoradiotherapy for locally advanced nasopharyngeal carcinoma with nodal stage N2-3. Jpn J Clin Oncol. 2017; 47: 705-712.

28. Qu D, Blanchard P, EI Khoury C, De Felice F, Even C, Levy A, Nguyen F, Janot F, Gorphe P, Deutsch E, Temam S, Tao Y. Induction chemotherapy with docetaxel, cisplatin and fluorouracil followed by concurrent chemoradiotherapy or chemoradiotherapy alone in locally advanced non-endemic nasopharyngeal carcinoma. Oral Oncol. 2016; 62: 114-121.

29. Bae WK, Hwang JE, Shim HJ, Cho SH, Lee JK, Lim SC, Chung WK, Chung IJ. Phase II study of docetaxel, cisplatin, and 5-FU induction chemotherapy followed by chemoradiotherapy in locoregionally advnced nasopharyngeal cancer. Cancer Chemother Pharmacol. 2010; 65: 589-595.

30. Fangzheng W, Chuner J, Zhiming Y, Tongxin L, Fengqin Y, Lei W, Bin L, Fujun H, Ming C, Weifeng Q, Zhenfu F. Long-term use of nimotuzumab in combination with intensity-modulated radiotherapy and chemotherapy in the treatment of locoregionally advanced nasopharyngeal carcinoma: experience of a single institution. Oncol Res. 2017. https://doi.org/10.372/096504017X15079846743590.

31. Fangzheng W, Quanquan S, Chuner J, Lei W, Fengqin Y, Zhimin Y, Tongxin L, Min X, Peng W, Haitao J, Aizawa R, Sakamoto M, Yuezhen W, Zhenfu F. Gemcitabine/cisplatin induction chemotherapy before concurrent chemotherapy and intensity-modulated radiotherapy improves outcomes for locoregionally advanced nasopharyngeal carcinoma. Oncotarget. 2017; 8: 96798-96808. https://doi. org/10.18632/oncotarget.18245.

32. Fangzheng W, Chuner J, Zhimin Y, Quanquan S, Tongxin L, Min X, Peng W, Bin L, Sakamoto M, Yuezhen W, Fengqin Y, Zhenfu F, Yangming J. Association of the neoadjuvant chemotherapy cycle with survival outcomes in patients with locoregionally advanced nasopharyngeal carcinoma: a propensity-matched analysis. Oncotarget. 2017; 8: 9411794128. https://doi.org/10.18632/oncotarget.21587.

33. Wang FZ, Jiang CE, Ye ZM, Sun QQ, Liu TX, Xu M, $\mathrm{Wu}$ P, Shi KY, Long B, Rihito A, Masoto S, Fu ZF. Efficacy and safety of nimotuzumab with neoadjuvant chemotherapy followed by concurrent chemoradiotherapy for locoregionally advanced nasopharyngeal carcinoma. Oncotarget. 2017; 8: 75544-75556. https://doi. org/10.18632/oncotarget.17357. 